\title{
A Comparative Study of Electrochemical and Optical Properties of Rhenium Deposited on Gold and Platinum
}

\author{
Jorge O. Zerbino ${ }^{a}$, Ana M. Castro Luna ${ }^{a}$, Carlos F. Zinola ${ }^{b}, E_{d u a r d o}$ Méndez $^{b}$ and M. E. Martins ${ }^{*, a}$ \\ ${ }^{a}$ INIFTA, Universidad Nacional de La Plata, Sucursal 4, C.C. 16 (CP 1900), La Plata, Argentina \\ ${ }^{b}$ Laboratorio de Electroquímica Fundamental, Facultad de Ciencias, Iguá 4225, Universidad de la República, \\ Montevideo, CP 11400, Uruguay
}

\begin{abstract}
Filmes de rênio e de óxido de rênio foram depositados sobre eletrodos de ouro e platina aplicando polarizações potenciostáticas e potenciodinâmicas numa região compreendida entre $-0,20 \mathrm{~V}$ e 0,70 $\mathrm{V}$ (vs rhe) em meio aquoso ácido contendo íons perrenato. As espessuras e as variáveis óticas dos filmes foram obtidas empregando perturbações triangulares de potencial e técnicas elipsométricas. Sobre eletrodos de ouro foi depositado rênio metálico na região de potencial de formação de hidrogênio molecular. Sobre eletrodos de platina foi formado óxido de rênio na região de adsorção de átomos de hidrogênio e rênio metálico juntamente com a formação de hidrogênio adsorvido e molecular sobre o mesmo metal.
\end{abstract}

Rhenium-containing films were grown on gold and platinum after different potentiostatic and potentiodynamic polarizations in the $-0.20 \mathrm{~V}$ to $0.70 \mathrm{~V}$ range ( $v s$ rhe $)$ in aqueous acid perrhenate. Experimental data were obtained using cyclic voltammetry and ellipsometry, from which the thickness and optical indices of the electrodeposited rhenium layer were calculated. Metallic rhenium deposition on gold takes place at potentials within the hydrogen evolution reaction. Rhenium oxide on platinum is formed in the hydrogen adatom potential domain, whereas metallic rhenium is deposited concurrently with the hydrogen adsorption and evolution reactions on the same metal.

Keywords: rhenium, gold, platinum, voltammetry, ellipsometry

\section{Introduction}

The electrochemistry of rhenium has been the subject of different studies because of its catalytic properties in fuel cell electrodes and as a coordination compound in radiopharmacy. ${ }^{1-3}$ The electrodeposition of rhenium species on gold from aqueous perrhenate solutions has been investigated by Horanyi et al. ${ }^{4}$ concluding that metallic rhenium is deposited at potentials within the hydrogen evolution region. By using an electrochemical quartz microbalance, ${ }^{5}$ it has been found that rhenium deposition occurs through a mechanism of progressive nucleation, which changes from two-dimensional to three-dimensional growth, under diffusion control. However, the nature of the adsorbed layer has not been yet identified. ${ }^{5}$ On platinum, on the other hand, some kind of oxygencontaining rhenium species has been detected, probably

\footnotetext{
*e-mail: mmartins@inifta.unlp.edu.ar
}

$\mathrm{ReO}_{2} \cdot{ }^{6}$ It has been suggested that prior to hydrogen electroadsorption $\mathrm{ReO}_{2}$ adsorption takes place, and after the layer completion, bulk phases of $\mathrm{ReO}_{2}$ and $\mathrm{ReO}_{3}$ can be also observed. ${ }^{7}$

In the present work additional information obtained by spectroscopic in situ ellipsometry may contribute to solve the controversy still existing about the nature of the electrodeposited layer both on platinum and on gold.

\section{Experimental}

The electrochemical and ellipsometric studies were performed using a three-electrode optical cell as previously reported. ${ }^{8}$ Polycrystalline $(p c)$ gold and platinum disks (0.95 and $1.05 \mathrm{~cm}^{2}$ real area) were used as working electrodes, which were mirror polished with fine grade alumina powders $(0.3$ and $0.05 \mathrm{~mm})$. A large gold or platinum gauze was used as counter electrode and a reversible hydrogen electrode (rhe) as reference.

Aqueous $1 \mathrm{~mol} \mathrm{~L}^{-1} \mathrm{H}_{2} \mathrm{SO}_{4}$ (T. J. Baker, ACS reagent) and 
$10^{-3} \mathrm{~mol} \mathrm{~L}^{-1}$ aqueous $\mathrm{NH}_{4} \mathrm{ReO}_{4}$ (Aldrich, $99+\%$ ) in $1 \mathrm{~mol}$ $\mathrm{L}^{-1} \mathrm{H}_{2} \mathrm{SO}_{4}$ were used as supporting electrolyte and working solution, respectively. Solutions were prepared from analytical quality chemicals reagent and Millipore-MilliQ* water. All runs were performed under oxygen-free nitrogen gas saturation, at $298 \mathrm{~K}$. Potentials in the text are given on the reversible hydrogen electrode (rhe) scale.

Cyclic voltammetry was performed with $p c$ gold or platinum electrodes in the supporting electrolyte and in the working solution at a potential scan rate $(v)=0.1 \mathrm{~V} \mathrm{~s}^{-1}$. Voltammetric runs included repetitive triangular potential scans and potential holdings in the $-0.20 \mathrm{~V}$ to $0.40 \mathrm{~V}$ range for a fixed time $\tau$.

Ellipsometry was performed illuminating the electrode with monochromatic light in the visible wavelength range $(400 \mathrm{~nm} \leq l \leq 700 \mathrm{~nm})$ with an incident angle of 70 degrees. The ellipsometric parameters $\Delta$ and $\psi$ were measured at different $\lambda$, i.e. $405,450,492,546$ and $580 \mathrm{~nm}$.

Different experimental procedures were applied for electrochemical and ellipsometric measurements depending on the nature of the electrode surface.

\section{Gold electrodes}

Procedure A. The electrode potential was held in the $-0.20 \mathrm{~V} \leq E_{c} \leq 0.20 \mathrm{~V}$ range for a time $\tau$. Later, a second potential holding at $E_{c}=0.10 \mathrm{~V}$ was applied for $\tau=10 \mathrm{~min}$ under nitrogen bubbling, allowing the electrooxidation of molecular hydrogen previously formed. Finally, repetitive triangular potential scans were applied from $E_{c}=0.10 \mathrm{~V}$ to $E_{a}=1.70 \mathrm{~V}$.

Procedure B. First, a potential holding at $E_{a}=1.20 \mathrm{~V}$ for $\tau=3$ min was adjusted in the cell. Then, a potential scan at a sweep rate $v=5 \times 10^{-4} \mathrm{~V} \mathrm{~s}^{-1}$ from $E_{a}$ to a cathodic potential $E$ located within the $-0.20 \mathrm{~V} \leq E \leq 0.20 \mathrm{~V}$ range was applied. After reaching $E$ and holding the potential for $\tau=10 \mathrm{~min}$, an upscan from $E$ to $E_{a}$ was subsequently performed. Ellipsometric parameters $\Delta$ and $\psi$ were recorded when applying the potential routine, as a function of potential $E$ and time $t$.

\section{Platinum electrodes}

Procedure $C$. Ellipsometric parameters $\Delta$ and $\psi$ were recorded as a function of the potential $E$ at $v=5 \times 10^{-4} \mathrm{~V} \mathrm{~s}^{-1}$ from $E_{a}=0.70 \mathrm{~V}$ to $E_{c}=0.03 \mathrm{~V}$ and subsequently an upscan was applied from $E_{c}$ to $E_{a}$.

Procedure $D$. The electrode potential was held in the $0.03 \mathrm{~V} \leq E \leq 0.15 \mathrm{~V}$ range for a time $\tau=10 \mathrm{~min}$. The ellipsometric parameters $\Delta$ and $\psi$ were recorded at the five wavelenghts and at different selected potentials.

\section{Results and Discussion}

\section{Electrochemical and optical behaviour of rhenium species} on gold

Cyclic voltammograms of $p c$ gold in the working solution run at $v=0.10 \mathrm{Vs}^{-1}$ after holding the potential at $E=-0.15 \mathrm{~V}$ and subsequently at $E=0.10 \mathrm{~V}$ for $\tau=3$ and $10 \mathrm{~min}$ are shown in Figure 1 (Procedure A). The first increasing potential scan covering a potential domain from $0.15 \mathrm{~V}$ to $1.70 \mathrm{~V}$, exhibits a complex anodic profile, where two current peaks at $0.75 \mathrm{~V}$ and $0.88 \mathrm{~V}$ are observed. The current contribution at $E>1.30 \mathrm{~V}$ corresponds to the oxygen electrosorption. The second and the following cyclic potential scans run up to $1.70 \mathrm{~V}$ reveal that the anodic contributions within the $0.15 \mathrm{~V}$ to $1.20 \mathrm{~V}$ range, which are ascribed to adsorbed rhenium species, are no longer observed.

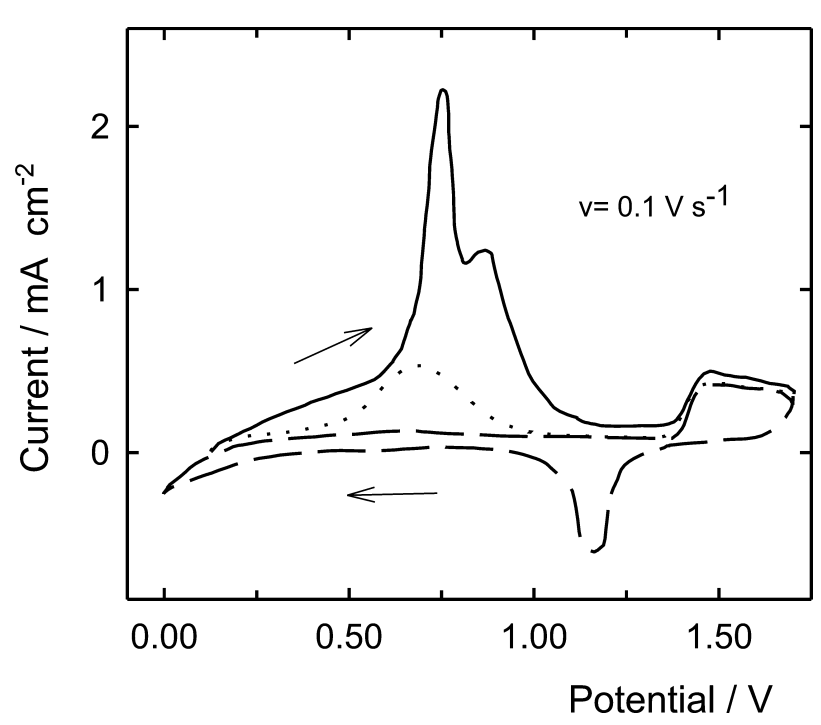

Figure 1. Cyclic voltammogram of $p c$ gold in aqueous $10^{-3} \mathrm{~mol} \mathrm{~L}^{-1}$ $\mathrm{ReO}_{4}^{-}+1 \mathrm{~mol} \mathrm{~L}^{-1} \quad \mathrm{H}_{2} \mathrm{SO}_{4}$ after holding the potential at $E_{c}=-0.15 \mathrm{~V}$ and subsequently at $E=0.10 \mathrm{~V}$ for $\tau=3 \mathrm{~min}(. . \ldots \ldots .$.$) and for \tau=10$ $\min (-)$. The second potential scan is denoted as (- - -). $v=0.10$ $\mathrm{V} \mathrm{s}^{-1} \cdot \mathrm{T}=298 \mathrm{~K}$.

The evolution of the ellipsometric parameters $\Delta$ and $\Psi$, obtained applying a decreasing potential scan from $E_{a}=1.20 \mathrm{~V}$ to a cathodic potential limit $E_{c}=-0.20 \mathrm{~V}$, is shown in Figures 2a an 2c, respectively (Procedure B). The $\Delta$ and $\Psi$ values remain nearly constant throughout the decreasing potential scan (Figure 2a). Moreover, when $E_{c}$ is applied $\Delta$ remains stable for times $\tau<3$ min, while for longer $\tau, \Delta$ continuously decreases (Figure $2 \mathrm{~b}$ ). Afterwards, during the following positive going potential sweep, $\Delta$ still decreases until achieving a constant $\Delta$ value within the region $0.10 \mathrm{~V} \leq E \leq 0.60 \mathrm{~V}$. Finally, for $E>0.60 \mathrm{~V}, \Delta$ 
increases reaching the initial $\Delta$ and $\Psi$ values (Figures 2 a and 2c). At $E=-0.20 \mathrm{~V}, \Delta$ exhibits a decrease equal to 8.7 degrees while during the upscan $\Psi$ remains almost constant (Figures $2 \mathrm{c}$ and $2 \mathrm{~d}$ ). The $\Delta$ behaviour indicates that rhenium-containing species are totally desorbed from the surface during the subsequent upscan.



Figure 2. Evolution of ellipsometric parameters $\Delta$ and $\Psi$ for the following sequence: $(\mathrm{a}, \mathrm{c})$ down scan from $E_{a}=1.2 \mathrm{~V}$ to $E_{c}=-0.20$ $\mathrm{V}(\diamond), v=210^{-3} \mathrm{Vs}^{-1}$; (b,d) a potential holding for $t=10 \mathrm{~min}$ at $E_{c}=$ $-0.20 \mathrm{~V}(\bullet) ;(\mathrm{a}, \mathrm{c})$ upscan from $E_{c}=-0.20 \mathrm{~V}$ to $E_{a}=1.2 \mathrm{~V}(\mathrm{o}), v=2$ $10^{-3} \mathrm{~V} \mathrm{~s}^{-1}$. Gold in aqueous $10^{-3} \mathrm{~mol} \mathrm{~L}^{-1} \mathrm{ReO}_{4}^{-}+1 \mathrm{~mol} \mathrm{~L}^{-1} \mathrm{H}_{2} \mathrm{SO}_{4}$. $\lambda=546 \mathrm{~nm} . \mathrm{T}=298 \mathrm{~K}$.

The comparison between ellipsometric results and theoretical calculations considering the growth of an isotropic and homogeneous ${ }^{8}$ layer allows a quantitative description of the electrodeposition process. For these interfaces the decrease in $\Delta$ ( $\Psi$ remaining nearly constant) may be considered as a measure of the increase in the layer thickness, $d$.

Optical indices $(n-\mathrm{i} k$ ) and the $d$ values of the grown layer are evaluated using $\Delta / \Psi$ pairs of data measured at five $\lambda_{i}$. This set of optical data allows the unequivocal determination of $d, n$ (refractive index) and $k$ (light absorption coefficient). Furthermore, optical indices are calculated assuming the formation of a single homogeneous film of constant composition and different thicknesses according to literature. ${ }^{8}$ The program employed for calculations uses the subroutine $I B M-D F M C G^{9}$ that finds the local minimum of a complex function of several variables by the conjugated gradients method. For each $\lambda_{i}$ the experimental values corresponding to five film thicknesses $d_{i}$ were fitted for a single pair of optical indices $n_{i}$ and $k_{i}$. Simultaneously, for each value of $d_{j}$, the optical data measured at different $\lambda_{i}$ must fit the same $d_{j}$ value.

The calculated values of thickness $d$ are plotted as a function of $E_{c}$ (Figure 3 ). There is a general agreement that a metallic rhenium electrodeposit is obtained by applying

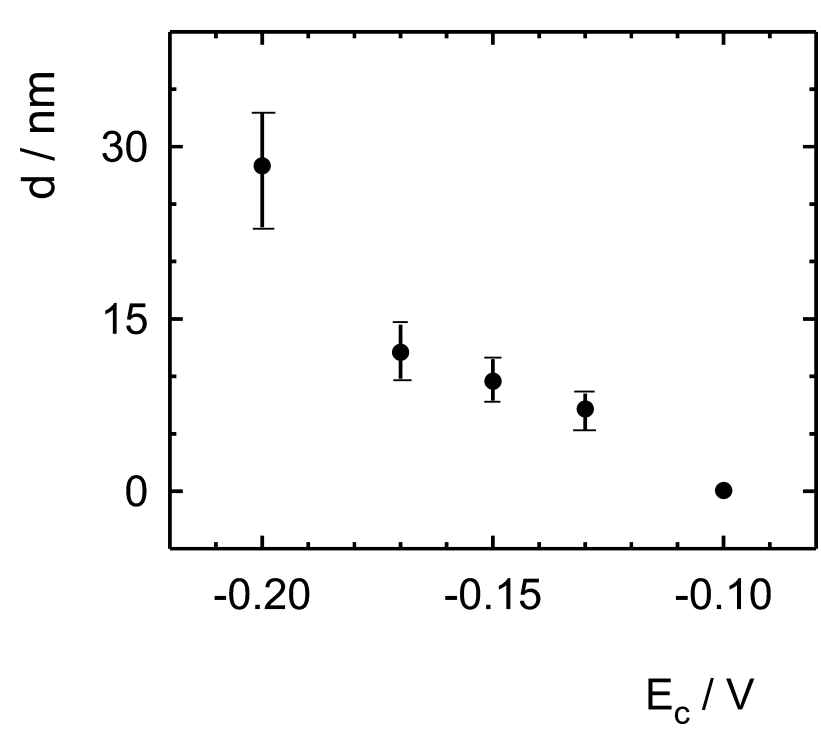

Figure 3. Thickness $d$ of the adsorbed layer $v s E_{c}$ calculated from ellipsometric data.

relatively high cathodic currents whereas rheniun oxide layers are possibly formed under milder reduction conditions. ${ }^{6}$

The optical indices of rhenium oxide have been reported ${ }^{10}$ resulting $k$ values in the range $0.3 \leq k \leq 0.5$ for $\lambda$ within $400 \mathrm{~nm} \leq \lambda \leq 546 \mathrm{~nm}$. Taking into account that these $k$ values are lower than those experimentally obtained for the same $\lambda$ region, $0.4 \leq k \leq 0.9$, the possibility of rhenium oxide layer formation on gold is excluded. Besides, this result suggests the growth of a porous metal layer or a composite metal/electrolyte layer which may have higher absorption $k$ indices. Therefore, $n$ and $k$ values are compared with those obtained through the Bruggeman Effective Medium Theory (EMT) for an ideal mixture of metallic rhenium and water or metallic rhenium and hydrogen as a function of the volumetric fraction $Q$ (metal/ electrolyte, metal/vacuum). ${ }^{11}$ These calculations are shown in Figure 4 where it is assumed: $i$ ) the formation of a composite of rhenium and water, and $i$ ) the formation of a composite of metallic rhenium and residual molecular hydrogen gas trapped in the grown layer on $p c$ gold. On the other hand, the values of effective optical indices predicted by the Maxwell Garnet Theory $(M G T)$ for either metallic grains dispersed in a hydrogen matrix or voids filled with molecular hydrogen embedded in a metallic matrix were also calculated ${ }^{12}$ (Table 1).

These data demonstrate a good agreement regarding the values of $n$ and $k$ predicted either by the EMT or the $M G T$ considering hydrogen voids immersed in the metallic matrix. The calculated indices show a good agreement with the latter proposal resulting in a $Q$ fraction of about $30 \%$. On the other hand, when metallic grains immersed 


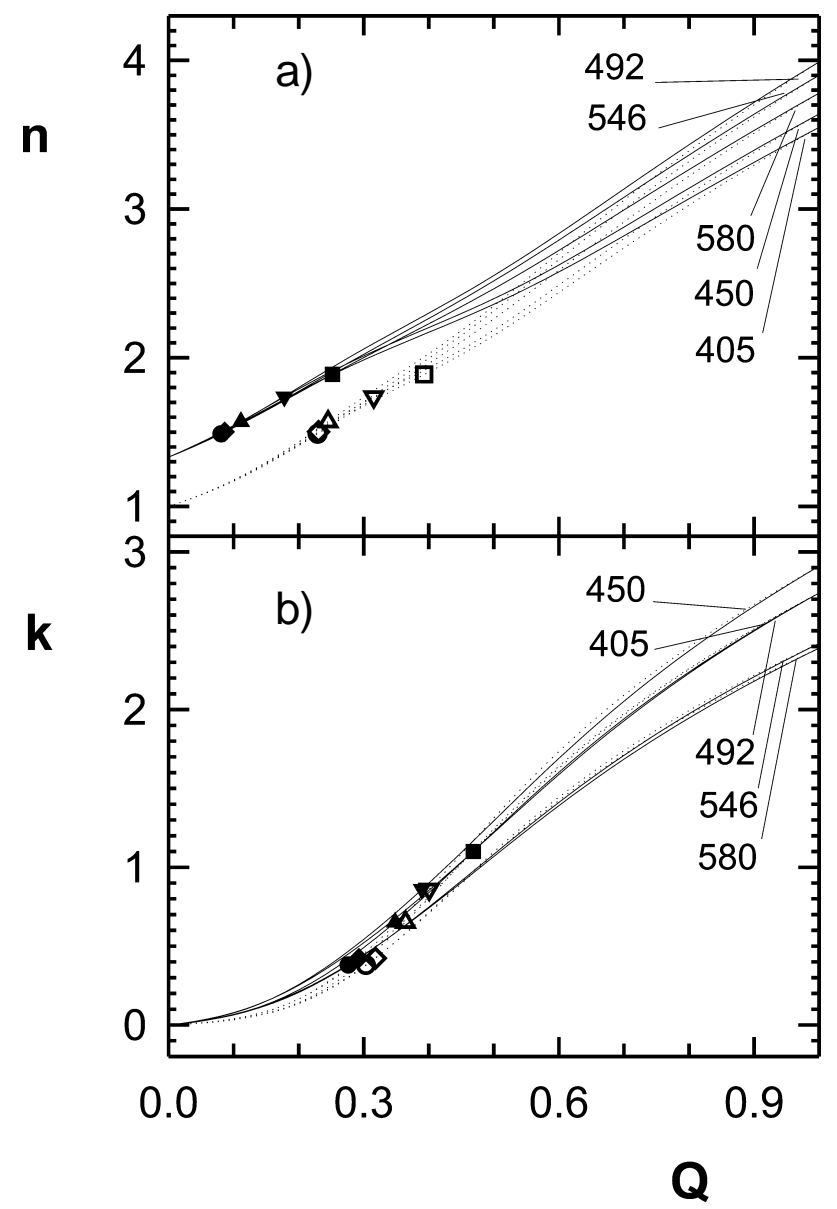

Figure 4. (a) $\boldsymbol{n}$ and (b) $\boldsymbol{k}$ values predicted by the Bruggeman Effective Medium Theory for the case of (1) the composite metallic rhenium and electrolyte $v s$ the volumetric fraction $Q,(-) ; \lambda=$

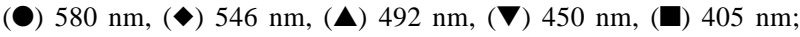
and for (2) the composite metallic rhenium and occluded hydrogen vs the volumetric fraction $Q,(\ldots \ldots \ldots), \lambda=(\bigcirc) 580 \mathrm{~nm},(\diamond) 546 \mathrm{~nm}$, ( $\Delta) 492 \mathrm{~nm},(\nabla) 450 \mathrm{~nm},(\square) 405 \mathrm{~nm}$. Symbols correspond to the experimental $n$ and $k$ obtained after data analysis. Gold in aqueous $10^{-3} \mathrm{~mol} \mathrm{~L}^{-1} \quad \mathrm{ReO}_{4}^{-}+1 \mathrm{~mol} \mathrm{~L}^{-1} \mathrm{H}_{2} \mathrm{SO}_{4} \cdot \mathrm{T}=298 \mathrm{~K}$.

in a hydrogen matrix are taken into account, it results in a larger dispersion of the predicted $Q$ values. This fact provides further evidence that the voids filled with hydrogen embedded in a metallic matrix suit an appropriated theory. In spite of the small differences between the predicted $Q$ values by the EMT and the $M G T$ for the different $\lambda_{i}$ values, the comparison of data leads to an estimate of $Q$ value between $20 \%$ and $30 \%$, corresponding to a composite formed by metallic rhenium with occluded hydrogen.

\section{Electrochemical and optical behaviour of rhenium species on platinum}

Cyclic voltammograms of smooth $p c$ platinum in the working solution run at $v=0.10 \mathrm{~V} \mathrm{~s}^{-1}$ from
$0.05 \mathrm{~V} \leq E_{\mathrm{c}} \leq 0.50 \mathrm{~V}$ up to $E_{\mathrm{a}}=1.40 \mathrm{~V}$ are shown in Figure 5. They exhibit a complex anodic current peak at $0.57 \mathrm{~V}\left(I_{a}\right)$ and a broad cathodic current peak extending from $0.60 \mathrm{~V}$ to $0.05 \mathrm{~V}\left(I_{c}\right)$. Furthermore, a total blockage of hydrogen electrodesorption and a distorted profile of oxygen electroadsorption are observed, probably due to rhenium species competing for platinum surface sites. The gradual decrease of $E_{\mathrm{c}}$ from $0.50 \mathrm{~V}$ to $0.05 \mathrm{~V}$ results in a corresponding gradual growth of the anodic charge related to peak $I_{a}$, confirming that the broad cathodic current extending from $0.05 \mathrm{~V}$ to $0.60 \mathrm{~V}$ is related to the electrodeposition of rhenium species. Hence, these species are probably responsible of the hindrance of the hydrogen electrosorption reaction, as revealed through the feeble hydrogen electrodesorption current peaks (Figure 5).

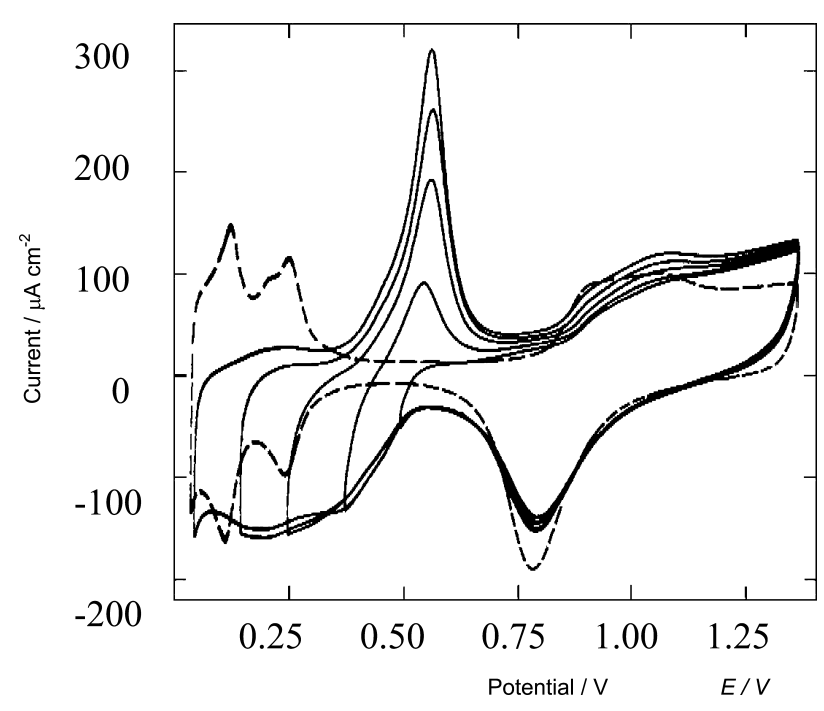

Figure 5. Cyclic voltammograms of smooth $p c$ platinum in aqueous $10^{-3} \mathrm{~mol} \mathrm{~L}^{-1} \mathrm{ReO}_{4}^{-}+1 \mathrm{~mol} \mathrm{~L}^{-1} \mathrm{H}_{2} \mathrm{SO}_{4}(-)$ and in aqueous $1 \mathrm{~mol} \mathrm{~L}^{-1}$ $\mathrm{H}_{2} \mathrm{SO}_{4}$ (- - -) with a gradual change of $E_{c} \cdot v=0.10 \mathrm{Vs}^{-1} \cdot \mathrm{T}=298 \mathrm{~K}$.

The evolution of $\Delta$ and $\Psi$ during a negative going potential scan from $0.70 \mathrm{~V}$ to $0.03 \mathrm{~V}$ (Procedure $\mathrm{C}$ ) is shown in Figure 6. In the same figure $\Delta$ and $\Psi$ values measured at $E_{c}=0.20,0.10,0.03,0.45$ and $0.70 \mathrm{~V}$, either after $\tau=1 \mathrm{~min}$ or $\tau=10 \mathrm{~min}$, are also shown (Procedure D). The optical parameters in the supporting electrolyte, remain practically constant both in the double layer and hydrogen adatom potential domains $(0.03 \mathrm{~V}<E<0.70 \mathrm{~V})^{15,16}$ and in the working solution a decrease in $\Delta$ for $E<0.20 \mathrm{~V}$ is observed. Besides, $\Delta$ values remain constant during the early steps of the positive potential scan, but increase for $E>0.25 \mathrm{~V}$ reaching at $E=0.70 \mathrm{~V}$ similar values to those observed on the freshly polished electrode. A decrease of about 0.1 degrees in $\Psi$ is observed at $0.70 \mathrm{~V}$ after a potential cycle (Figure 6). 




Figure 6. Evolution of ellipsometric parameters $\Delta$ and $\Psi$ for the following sequence: $(\diamond)$ down scan from $E_{a}=0.70 \mathrm{~V}$ to $E_{c}=0.03 \mathrm{~V}$; (o) upscan from $E_{c}=0.03 \mathrm{~V}$ to $E_{a}=0.70 \mathrm{~V}, v=510^{-4} \mathrm{Vs}^{-1}$, (Procedure C). Full marks corresponds to measurements according to Procedure $\mathrm{D},(\boldsymbol{\bullet}) \tau=1 \mathrm{~min},(\boldsymbol{\nabla}) \tau=10 \mathrm{~min}$. Platinum in aqueous $10^{-3} \mathrm{~mol} \mathrm{~L}^{-1} \mathrm{ReO}_{4}^{-}+1 \mathrm{~mol} \mathrm{~L}^{-1} \mathrm{H}_{2} \mathrm{SO}_{4} \cdot \lambda=546 \mathrm{~nm} . \mathrm{T}=298 \mathrm{~K}$.

Furthermore, $\Delta$ and $\Psi$ values were also obtained after holding the potential at different $E_{c}$ for $t=10 \mathrm{~min}$ according to Procedure D (Figure 7). The values of $(d)$ and $(n-\mathrm{i} k)$ of the grown layer were evaluated using $\Delta$ and $\Psi$ data measured at the five wavelengths. Similarly to the methodology used for rhenium deposition on gold, the optical indices for platinum were calculated assuming the formation of a single homogeneous film of constant composition and different thicknesses. The program employed for the calculation also uses the subroutine IBM-DFMCG. ${ }^{9}$

In Figure 7 the calculated values of $\Delta$ and $\Psi$ for metallic rhenium, rhenium oxide and platinum oxide layers are plotted as a function of different volume fractions, namely, $Q_{o x^{\prime}}$ oxide/ electrolyte, and $Q_{m e r}$ metal/ electrolyte, using the effective optical indices predicted by the EMT. Table 1 shows the optical indices and the literature value ${ }^{13-16}$ used for the calculations. The optical indices for $\mathrm{ReO}_{2}$ are similar to those of $\mathrm{ReO}_{3}$ but exhibit lower $k$ values. ${ }^{10,14}$

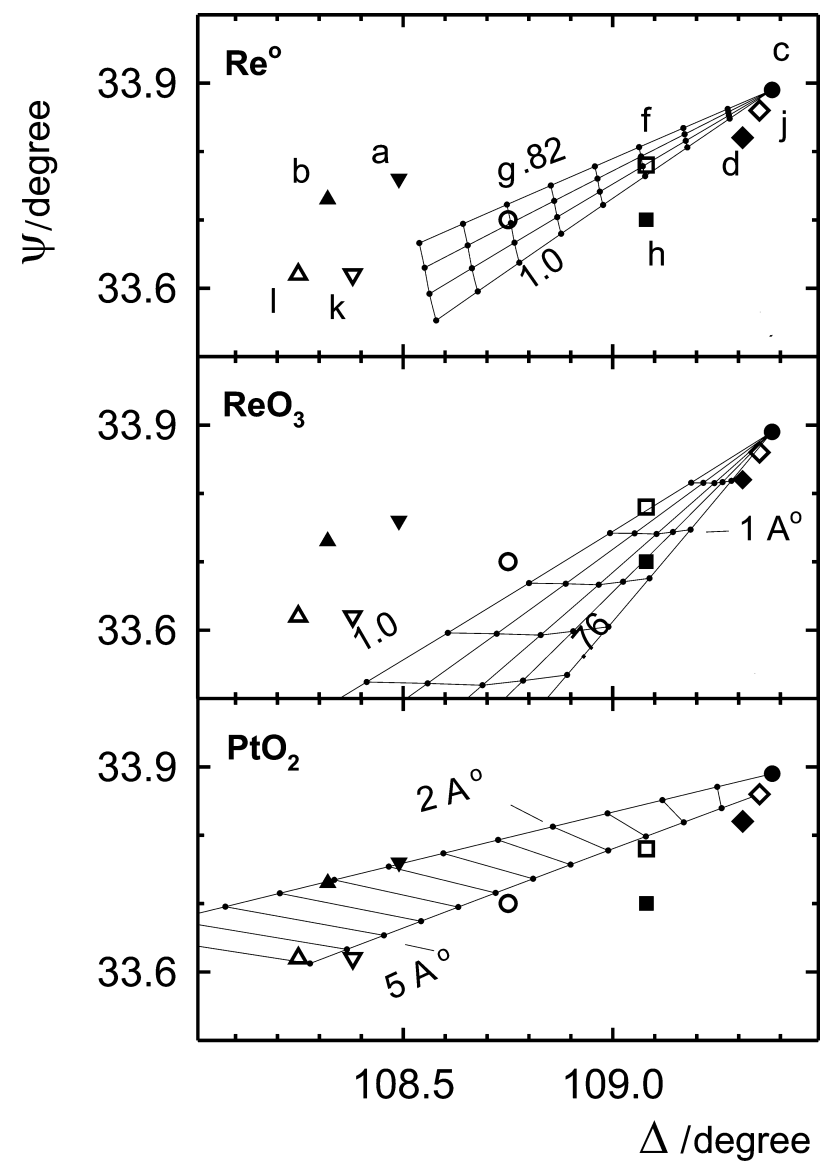

Figure 7. $\Delta$ and $\Psi$ measured at $\lambda=580 \mathrm{~nm}$ according to Procedure

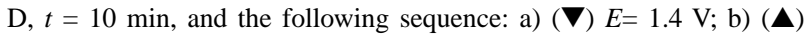
$E=1.5 \mathrm{~V}$; c) $(\bullet) E=0.70 \mathrm{~V}$; d) $(\diamond) E=0.20 \mathrm{~V}$; f) ( $\square) E=0.10 \mathrm{~V}$; g)

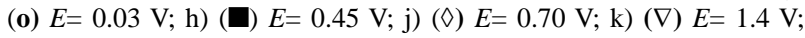
1) $(\Delta) E=1.5 \mathrm{~V}$. Plots include theoretical values predicted for the different layers, increasing $d$ on each $0.5 \AA$ A metallic rhenium, $Q=$ $1.00,0.94,0.88,0.82$; rhenium oxide, $Q=1.00,0.94,0.88,0.82$, 0.76 ; platinum oxide: $(\boldsymbol{\Delta}, \boldsymbol{\nabla}) n-\mathbf{i} k=3.38-\mathbf{i} 1.26 ;(\nabla, \Delta) n-\mathbf{i} k=$ $2.80-$ i 2.14 .

The optical measurements agree with the formation of a layer of about $0.5 \AA$ for $\mathrm{ReO}_{3}\left(Q_{o x}=0.76, n-\mathrm{i} k=0.89-\right.$ i 0.56) at $E=0.20 \mathrm{~V}, 3 \AA$ for metallic rhenium $\left(Q_{\text {met }}=0.88\right.$, $n-\mathrm{i} k=3.47-\mathrm{i} 2.13)$ at $E=0.03 \mathrm{~V}$ and $1.40 \AA$ for $\mathrm{ReO}_{3}$ $\left(Q_{o x}=0.82, n-\mathrm{i} k=0.85-\mathrm{i} 0.6\right)$ at $E=0.45 \mathrm{~V}$. The decrease of about 0.05 degrees observed at $0.70 \mathrm{~V}$ probably indicates that a small quantity of rhenium oxide remains on the

Table 1. Optical indices, $n$ and $k$, for metallic rhenium, rhenium oxide and platinum oxide for different values of wavelengths. $n_{\text {water }}=(1.332-\mathrm{i} 0.0)$, $\mathrm{n}_{\text {hydrogen }}=(1.0-\mathrm{i} 0.0)$

\begin{tabular}{ccccccccccccc}
\hline$\lambda / \mathrm{nm}$ & \multicolumn{2}{c}{405} & \multicolumn{2}{c}{450} & \multicolumn{2}{c}{492} & \multicolumn{2}{c}{546} & \multicolumn{2}{c}{580} & \multicolumn{2}{c}{ Ref. } \\
& $n$ & $n$ & $k$ & $n$ & $k$ & $n$ & $k$ & $n$ & $K$ & & $n$ \\
\hline $\operatorname{Re}$ & 3.55 & 2.74 & 3.64 & 2.91 & 3.99 & 2.74 & 3.90 & 2.42 & 3.78 & 2.39 \\
$\mathrm{ReO}_{3}$ & 2.46 & 0.507 & 2.22 & 0.338 & 1.57 & 0.285 & 0.850 & 0.471 & 0.707 & 0.700 & 13 \\
$\mathrm{PtO}_{2}$ & 2.10 & 2.20 & 2.30 & 2.30 & 2.40 & 2.50 & 2.50 & 2.70 & 2.40 & 2.80 & 15 \\
& 3.10 & 1.50 & 3.20 & 1.45 & 3.30 & 1.42 & 3.40 & 1.41 & 3.50 & 1.40 & 16 \\
\hline
\end{tabular}


platinum electrode after the potential cycling. Figure 7 also shows the fitting of $\Delta$ and $\Psi$ values corresponding to $\mathrm{PtO}_{2}$ layers at $E=1.40$ and $1.50 \mathrm{~V}$.

\section{Conclusions}

For gold electrodes rhenium deposition occurs simultaneously with hydrogen evolution reaction. A composite of metallic rhenium and occluded hydrogen is obtained with a rhenium volumetric fraction of about $30 \%$.

For platinum electrodes, rhenium oxide grows at potentials lower than $0.20 \mathrm{~V}$, whereas metallic rhenium is observed at potentials lower than $0.10 \mathrm{~V}$, simultaneously with the hydrogen adatom electrosorption reaction. Multilayer growth of metallic rhenium with thickness from $50 \AA$ to $300 \AA$ is observed at potentials lower than $-0.10 \mathrm{~V}$, while a monolayer growth of metallic rhenium occurs within the hydrogen adatom potential domain with thickness from $1.5 \AA$ to $3.0 \AA$.

These results clearly indicate the strong influence of the electric potential on the behaviour of rhenium deposition. Moreover, it is also noticeable the nature of the metal electrode, taking into account that different adsorption and /or catalytic reactions are probably involved.

\section{Acknowledgements}

This research project was financially supported by the "Comisión de Investigaciones Científicas de la Provincia de Buenos Aires", CIC, the "Consejo Nacional de Investigaciones Científicas y Técnicas", CONICET, Argentina, and the "Programa para el Desarrollo de las Ciencias Básicas", PEDECIBA, Uruguay. M. E. M. is a researcher at CONICET. A. M. C. L. and J. O. Z. are researchers at CIC.

\section{References}

1. Karasikov, V. L.; Elektrokhimiya 1981, 17, 1518.

2. Gómez, J.; Gardiazábal, J. I.; Schrebler, R.; Gómez, H.; Córdova, R.; J. Electroanal. Chem. 1989, 260, 113.

3. Horanyi, G.; Bakos, I.; Szabó, S.; Rizmayer, E. M.; J. Electroanal. Chem. 1992, 337, 365.

4. Bakos, I.; Horanyi, G.; Szabó, S.; Rizmayer, E. M.; J. Electroanal. Chem. 1993, 359, 241.

5. Schrebler, R.; Cury, P.; Orellana, M.; Gómez, H.; Córdova, R.; Dalchiele, E.; Electrochim. Acta 2001464309.

6. Szabó, S.; Bakos, I.; J. Electroanal. Chem. 2000, 492, 103.

7. Szabó, S.; Bakos, I. In Preparation of Catalysts VII. Studies in Surface Science and Catalysis; Delmon, E. B.; Jacobs, P.A. et al. eds. 1998, 118, 269.

8. Zerbino, J. O.; Florit, M. I.; Maltz, A.; Electrochim. Acta. 1999, 44, 1973.

9. Fletcher, R.; Reeves, C. M.; Computer J. 1964, 7, 149.

10. Krishna, M. G.; Bhattacharrya, A. K.; Solid. State Commun. 2000, 116, 637.

11. Aspnes, D. E. In Handbook of Optical Constants of Solids; Palik, E. D. ed., Acad. Press: New York, ch. 5, p. 89.

12. Zerbino, J.; Castro Luna, A. M.; Zinola, C. F.; Méndez, E.; Martins, M. E.; J. Electroanal. Chem. 2002, 521, 168.

13. CRC Handbook of Chem. and Phys., $73^{\text {rd }}$ ed., CRC Press: D. R. Lide 1993.

14. Feinleib, J.; Scouler, W. J.; Ferretti, A.; Phys. Rev. 1968, 165, 765.

15. Gottesfeld, S.; Maia, G.; Floriano, J. B.; Tremiliosi Filho, G.; Ticianelli, E. A.; Gonzalez, E. R.; J. Electrochem. Soc. 1991, $138,3219$.

16. Horkans, J.; Cahan, B. D.; Yeager, E.; Surf. Sci. 1974, 46, 1.

Received: January 18, 2002

Published on the web: July 26, 2002 